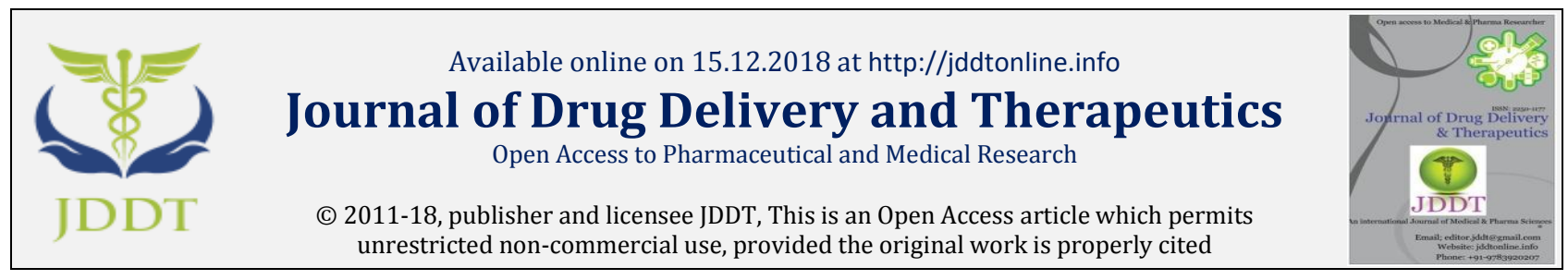

Open $\odot$ Access

Review Article

\title{
Sublingual route for systemic drug delivery
}

\author{
Pawar Poonam P*1, Ghorpade Hemant S. ${ }^{2}$, Kokane Bhavana A. ${ }^{3}$ \\ ${ }^{* 1}$ MABD Diploma College of Pharmacy, Yeola, Nasik (MH), India. \\ 2Production Department, FDC Ltd. Waluj, Aurangabad(MH), India. \\ ${ }^{3}$ MABD Diploma College of Pharmacy, Yeola, Nasik (MH), India.
}

\begin{abstract}
Drug delivery via the oral mucous membrane is considered to be a promising alternative to the oral route. Sublingual route is a rapid onset of action and better patient compliance than orally ingested tablets. Sublingual literally meaning is "under the tongue", administrating substance via mouth in such a way that the substance is rapidly absorbed via blood vessels under tongue. The portion of drug absorbed through the sublingual blood vessels bypasses the hepatic first-pass metabolic processes giving acceptable bioavailability. Sublingual technology is convenient for dosing in geriatric, pediatric and psychiatric patients with dysphagia. Sublingual drug delivery shows fast therapeutic action than orally ingested drugs with fewer side effects. This review highlights advantages, disadvantages, different sublingual Gland, sublingual formulation such as tablets, films drops, sprays etc, evaluation parameters.
\end{abstract}

Keywords: Sublingual delivery, dysphagia, sublingual gland, improved bioavailability, evaluations.

Article Info: Received 18 Oct, 2018; Review Completed 30 Nov 2018; Accepted 01 Dec 2018; Available online 15 Dec 2018

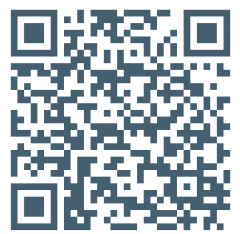

Cite this article as:

Pawar PP, Ghorpade HS, Kokane BA, Sublingual route for systemic drug delivery, Journal of Drug Delivery and Therapeutics. 2018; 8(6-s):340-343 DOI: http://dx.doi.org/10.22270/jddt.v8i6-s.2097

*Address for Correspondence:

Poonam P Pawar, MABD Diploma College of Pharmacy, Babhulgaon, Yeola, Nasik (MH), India.

\section{INTRODUCTION}

\section{Sublingual Drug Delivery \\ Definition}

"Systemic delivery of drugs through the mucosal membranes lining the floor of the mouth to the systemic circulation."

The systemic drug delivery provide immediate onset of pharmacological effects through the sublingual route. Dysphasia (Difficulty in swallowing) is common problem of all age groups or on reduced liquid intake have difficulties in swallowing the solid dosage forms. Sublingual administration of the drug means placement of drug i.e. dosage form under the tongue \& drug reaches directly into the systemic circulation. ${ }^{1,2}$

Sublingual drug delivery is alternative approach to the enteral drug delivery. It avoids first pass metabolism in liver and gastric acid hydrolysis of drugs therefore shows in increase in oral bioavailability of drugs.

\section{Principles}

When a chemical comes in contact with mucous membrane beneath the tongue, it diffuse

through it because of connective tissue beneath the epithelium contains a profusion of capillaries, the substance then diffuses into them and enters the venous circulation.
Drug solutes are rapidly absorbed into reticulated vein which is lies underneath the oral mucosa \& transported through the facial veins, internal jugular vein \& brachiocephalic vein $\&$ then enter in systemic circulation. ${ }^{3,4}$

\section{ADVANTAGES OF SUBLINGUAL DRUG DELIVERY ${ }^{5-7}$}

- It produces immediate systemic effect by enabling the drug absorbed quickly or directly through mucosal lining of the mouth beneath the tongue.

- Dose gets reduced.

- Onset of action is very fast.

- Improved bioavailability.

- Fewer side effects.

- Effective in disease like nausea, vomiting, migraine, schizophrenia.

- $\quad$ No need of water for administering tablet.

- $\quad$ Ease of drug administration gets increased.

- Sublingual area is much more permeable than buccal area.

- $\quad$ Bypass GI tract and hepatic portal system and avoid hepatic first pass metabolism due to this bioavailability of drug get increase.

- $\quad$ Rapid absorption due to high vascularization beneath the tongue.

- $\quad \mathrm{pH}$ in the mouth is relatively neutral so drug will be more stable.

- Improved patient compliance. 


\section{DISADVANTAGES OF SUBLINGUAL DRUG DELIVERY ${ }^{5-7}$}

- Unsuitable for uncooperative or unconscious patients.

- Unsuitable for bitter drugs.

- $\quad$ Poor Patient compliance.

- $\quad$ Eating, drinking, and smoking are not allowed.

- Administration of highly ionic drug is not allowed.

- Holding the dose in mouth is inconvenient, if any is swallowed that portion must be treated as an oral dose and subjected to first pass metabolism.

\section{SUBLINGUAL GLAND}

Salivary glands which are present in the floor of the mouth underneath the tongue. They are also known as sublingual glands. They produce mucin in turn produces saliva. The interior area of the mouth remains lubricated due to production of the saliva by the glands, which is necessary for chewing and food swallowing. Due to low secretion of the saliva it can create problem in swallowing the food and potential for food lodge in the throat increases. The absorption occurs by transfer of the drug from its site of administration into systemic circulation, so it can be said that absorption is directly proportional layer thickness. Due to high permeability and rich blood supply, the sublingual route can produce rapid onset of action so the drug with short delivery period can be delivered and dose regimen is frequent. The drug gets diluted in the saliva and from there the drug is adsorbed across the oral cavity. ${ }^{8}$

\section{SUBLINGUAL ABSORPTION}

\section{Mechanism of sublingual absorption}

Sublingual administration drug solutes are rapidly absorbed into the reticulated vein, which lies underneath the oral mucosa and transported through the facial veins, internal jugular vein and are then drained into the systemic circulation. Upon sublingual administration drug reaches directly into the blood stream through the ventral surface of the tongue and floor of the mouth. The main mechanism for the absorption of the drug into oral mucosa is via passive diffusion into the pilonidal membrane. ${ }^{5}$

\section{Factors affecting on sublingual absorption 4,8}

\section{- Solubility in Salivary Secretion}

In addition to high lipid solubility, the drug should be soluble in aqueous buccal fluids i.e. biphasic solubility of drug is necessary for absorption.

\section{- Binding to Oral Mucosa}

Systemic availability of drugs that bind to oral mucosa is poor.

\section{- $\quad$ pH and pKa of The Saliva}

As the mean $\mathrm{pH}$ of the saliva is 6.0 , this $\mathrm{pH}$ favors the absorption of drugs which remain unionized. Also, the absorption of the drugs through the oral mucosa occurs if the pKa is greater than 2 for an acid and less than 10 for a base.

\section{- $\quad$ Lipophilicity of Drug}

For a drug to be absorbed completely through sublingual route, the drug must have slightly higher lipid solubility than that required for GI absorption is necessary for passive permeation.

\section{- Thickness of Oral Epithelium}

As the thickness of sublingual epithelium is 100-200 $\mu \mathrm{m}$ which is less as compared to buccal thickness. So the absorption of drugs is faster due to thinner epithelium and also the immersion of drug in smaller volume of saliva.

\section{DRUGS FOR SUBLINGUAL ADMINISTRATION8-10}

Sublingual drug administration is applied in the field of cardiovascular drugs, steroids, some barbiturates and enzymes. The drugs with dose less than $20 \mathrm{mg}$ are suitable for sublingual drug delivery system. It has been a developing field in the administration of many vitamins and minerals which are found to be readily and thoroughly absorbed by this method. Sublingually absorbed nutrition, which avoids exposure to the gastric system and liver, means direct nutritional benefits, particularly important for sufferers of gastro-intestinal difficulties such as ulcers, hyperactive gut, coeliac disease, those with compromised digestion, the elderly and invalids the nutritional benefit is independent of gastro-intestinal influences. Examples of drugs administered by this route include antianginal like nitrites and nitrates, anti hypertensive like nifedipine, analgesics like morphine and bronchodilators like fenoterol. Certain steroids like estradiol and peptides like oxytocin can also be administered e.g. fentanyl

\section{SUBLINGUAL FORMULATIONS11-15}

- Sublingual Tablets

- Sublingual Films

- Multipurpose tablets

- Sublingual drops

- Sublingual spray

- Lozenge

- Effervescent sublingual tablets

\section{Sublingual Tablets}

"Sublingual tablets are solid unit dosage form meant for placement under the tongue to produce immediate action by avoiding the first pass effect of drug by liver."

The tablets are usually small and flat, compressed lightly to keep them soft. The tablet must dissolve quickly allowing the API to be absorbed quickly. It is designed to dissolve in small quantity of saliva. After the tablet is placed in the mouth below the tongue, the patient should avoid eating, drinking, smoking and possibly talking in order to keep the tablet in place. Swallowing of saliva should also be avoided since the saliva may contain dissolved drug. Bland excipients are used to avoid salivary stimulation. Nitroglycerine tablets and Ondansetron tablets (zopran) are the examples of sublingual tablets.

\section{Sublingual Films}

Mouth dissolving films or strip, a new drug delivery system for the oral delivery of the drugs, was developed based on the technology of the transdermal patch. The delivery system consists of a very thin oral strip, which is simply placed on the patient's tongue or any oral mucosal tissue, instantly wet by saliva the film rapidly hydrates and adheres onto the site of application. It then rapidly disintegrates and dissolves to release the medication for oromucosal absorption or with formula modifications, will maintain the quick-dissolving aspects allow for gastrointestinal absorption to be achieved when swallowed. Sublingual strips are similar to tablets in that they easily melt in the mouth and dissolve rapidly. Suboxone is an example of medication that comes in a sublingual strip. 


\section{Multi-Purpose Tablets}

Soluble tablets for either oral or sublingual administration, often also suitable for preparation of injections, Hydrostat (hydromorphone) and a number of brands of morphine tablets and cubes.

\section{Sublingual Drops}

Concentrated solutions to be dropped under the tongue, as with some nicocodeine cough preparatations.

\section{Sublingual Spray}

Spray for the tongue; certain human and veterinary drugs are dispensed as such.

\section{Lozenge}

Effects a metred and patient-controlled-rate combination of sublingual, buccal, and oral administration, as with the Actiq fentanyl lozenge-on-a-stick (lollipop).

\section{Effervescent Sublingual Tablets}

This method drives the drug through the mucous membranes much faster (this is the case in the stomach with carbonated or effervescent liquids as well) and is used in the Fentora fentanyl tablet.

\section{EVALUATION PARAMETERS16-22}

\section{General Appearance}

The general appearance of a tablet, its visual identity and over all "elegance" is essential for consumer acceptance. Include in are tablet's size, shape, color, presence or absence of an odor, taste, surface texture, physical flaws and consistency and legibility of any identifying marking.

\section{Size and Shape}

The size and shape of the tablet can be dimensionally described, monitored and controlled.

\section{Tablet Thickness}

Tablet thickness is an important characteristic in reproducing appearance and also in counting by using filling equipment. Some filling equipment utilizes the uniform thickness of the tablets as accounting mechanism.

\section{Wetting Time}

Using this test, the time required for moisture to penetrate the tablet completely is measured and possibly represents the time required to release drug in the presence of minute volumes of saliva.

A piece of tissue paper $(12 \mathrm{~cm} \mathrm{X} 10.75 \mathrm{~cm})$ folded twice was placed in a small Petri dish (ID $=6.5 \mathrm{~cm}$ ) containing 6 $\mathrm{ml}$ of Sorenson's buffer $\mathrm{pH}$ 6.8. A tablet was put on the paper, and the time for complete wetting was measured. Three trials for each batch and the standard deviation were also determined.

\section{Uniformity of Weight}

I.P. procedure for uniformity of weight was followed, twenty tablets were taken and their weight was determined individually and collectively on a digital weighing balance. The average weight of one tablet was determined from the collective weight.

Table 1: IP limit for weight variation

\begin{tabular}{|l|l|}
\hline Avg. Weight of Tablet & \% Variation Allowed \\
\hline $80 \mathrm{mg}$ or less & 10 \\
\hline $60 \mathrm{mg}$ but $<250 \mathrm{mg}$ & 7.5 \\
\hline $250 \mathrm{mg}$ or more & 5 \\
\hline
\end{tabular}

\section{Friability}

It is measured of mechanical strength of tablets. Roche friabilator can be used to determine the friability by following procedure. A preweighed tablet was placed in the friabilator. Friabilator consist of a plastic-chamber that revolves at $25 \mathrm{rpm}$, dropping those tablets at a distance of 6 inches with each revolution. The tablets were rotated in the friabilator for at least 4 minutes. At the end of test tablets were dusted and reweighed, the loss in the weight of tablet is the measure of friability and is expressed in percentage as $\%$ Friability $=$ loss in weight $/$ Initial weight $\mathrm{x}$ 100.

\section{Tablet Hardness}

Hardness of tablet is defined as the force applied across the diameter of the tablet in the order to break the tablet. The resistance of the tablet to chipping, abrasion or breakage under condition of storage transformation and handling before usage depends on its hardness. Hardness of the tablet of each formulation was determined using Monsanto Hardness tester.

\section{In-Vitro Dispersion Time}

In-vitro dispersion time can be measured by dropping a tablet in a beaker containing $50 \mathrm{ml}$ of Sorenson's buffer $\mathrm{pH}$ 6.8 .

\section{In-Vitro Disintegration Test}

The test can be carry out on 6 tablets using the apparatus specified in I.P. 1996 distilled water at $37^{\circ} \mathrm{C} \pm 2^{\circ} \mathrm{C}$ was used as a disintegration media and the time in second taken for complete disintegration of the tablet with no palable mass remaining in the apparatus measure in seconds.

\section{CONCLUSION}

Sublingual drug delivery has been used for formulation of many drugs with view point of rapid drug release and quick onset of action. Sublingual products were developed to overcome the difficulty in swallowing conventional tablet, among pediatric, geriatric and psychiatric patients with dysphagia. The potential for such dosage forms is promising because strong market acceptance and patient demand. Peak blood levels of most products administered sublingually are achieved within few minutes, which is generally much faster than when those same drugs are ingested orally. Sublingual absorption is efficient. The percent of each dose absorbed is generally higher than that achieved by means of oral ingestion. Various types of sublingual dosage forms are available in market like tablets, films, sprays, Drops, Lozenge etc. 


\section{REFERENCES}

1. Bind AK, Gnanarajan G, Kothiyal P, Sublingual route for systemic drug delivery: A Pharmaceutical Review, International Journal of Drug Research and Technology, 2013; 3(2):31-36.

2. Singh B, Gupta S, Kumar A, Fabrication and evaluation of sublingual tablets of telmisartan using different superdisintegrants: formulation and evaluation, International Journal of Pharmacy and Pharmaceutical Research, 2015; 3(1):201-218.

3. Pawar PP, Gaikwad SS, Patil PB, Design and development of sublingual tablets of ondansetron hydrochloride: formulation and evaluation, World Journal of Pharmacy and Pharmaceutical Sciences, 2016; 5(12):733-745.

4. Shah S, Badola A, Kothiyal P, Sublingual tablets an overview: A pharmaceuitical review, Indian Journal of Pharmaceutical and Biological Research, 2016; 4(2):20-26.

5. Singh M, Chitranshi N, Singh AP, Arora V, Siddiqi AW, An overview on fast disintegrating sublingual tablets: A pharmaceuitical review International Journal of drug delivery, 2012; 4(4):407-417.

6. Narang N, Sharma J, Sublingual mucosa as a route for systemic drug delivery: A pharmaceuitical review, International Journal of Pharmacy and Pharmaceutical Sciences, 2011; 3(2):18-22.

7. Patel P, Makwana S, Jobanputra U et al, Sublingual route for systemic delivery of ondansetron: A pharmaceuitical review, International Journal of Drug Development and Research, 2011; 3(4):36-40.

8. Sarkhejiya NA, Patel VP, Pandya DJ, Sublingual delivery A promising approach to improve bioavailability: A pharmaceuitical review, Pharma Sciences an International Journal of Pharmaceutical Sciences, 2013; 4(2):3870-3889.

9. Kavitha K, Subramaniam K, Hui BJ, et al, Potential drug candidate for fast dissolving drug delivery: A pharmaceuitical review, Research Journal of Pharmaceutical, Biological and Chemical Sciences, 2013; 4(4):1510-1526.

10. Vilayat AS, Mohammad A, Considerations in developing sublingual tablets: A pharmaceuitical review, PharmTech Advancing Development and Manufacturing, 2014; 38(11).

11. Patel KN, Pancholi SS, Sublingual route for systemic drug delivery: A pharmaceuitical review, International Journal of Research in Pharmaceutical and biomedical Sciences, 2012; 3(2):913-923.

12. Arya A, Chandra A, Sharma V, Pathak K, Fast dissolving oral film an innovative drug delivery system and dosage form: A pharmaceuitical review, International Journal of ChemTech Research, 2010; 2(1):576-583.

13. Kapadia YD, Sodha HP, Patel VP, Formulation development and evaluation of sublingual film of asenapine maleate: formulation and evaluation, Pharma Science Monitor an international Journal of Pharmaceutical Science, 2013; 4(3):190-209.

14. Siddiqui N, Garg G, Sharma PK, A novel approach in oral fast dissolving drug delivery system and their patents: A pharmaceuitical review, Advances in Biological research, 2011; 5(6):291-303.

15. Lachman L, Liebermann HA, Kanig JL.The Theory and Practice of Industrial Pharmacy, $3^{\text {rd }}$ ed. Mumbai: Varghese Publishing House1990. P. 479-488.

16. Indian Pharmacopoeia, Controller of publications, Govt. of India Ministry of health and family welfare, New Delhi, 1996. P. A-147.

17. United State Pharmacopoeia 30NF25, the official compendia of standards, Asian edition, United States Pharmacopoeial convection Inc. Rockville MD 2009. P. 276-383,617-658,806$807,817,1764,2492-2495$

18. Pethe AM, Salunkhe SP, Formulation and evaluation of mucoadhesive buccal tablet of simvastatin: formulation and evaluation, International Journal of Pharma and Bio Science, 2014, 5(3), 268-278.

19. Deshmukh G, Ruikar D, Seth AK et al, Formulation and development of lamotrigine fast disintegrating tablet: formulation and evaluation, Pharma Science Monitor an International Journal of Pharmaceutical Sciences, 2011; 2(2):S7-S15.

20. Nagar P, Singh K, Chauhan I et al, Orally disintegrating tablets: Formulation, preparation techniques and evaluation: A pharmaceutical review, Journal of Applied Pharamaceutical Science, 2011; 1(4):35-45.

21. Gaikwad SS, Jadhav AA, Chavan MK et al, Design and In-vitro evaluation of sublingual tablets of timolol maleate: formulation and evaluation, Bentham Science Applied clinical Research, Clinical Trials and Regulatory Affairs, 2016; 3(1):56-63.

22. Senthil A, Navinchandra CP, Jose J, Mahim MM, Ravajibhai SY Preparation and evaluation of timolol maleate mucoadhesive buccal tablets: formulation and evaluation, International Research Journal of Pharmacy, 2012; 3(3):292-297. 